\title{
Predictors of early rebleeding and mortality after acute variceal haemorrhage in patients with cirrhosis"
}

\author{
Iliass Charif", Kaoutar Saada, Ihsane Mellouki, Mounia El Yousfi, Dafr Allah Benajah, \\ Mohamed El Abkari, Adil Ibrahimi, Nourdin Aqodad
}

Department of Hepatology and Gastroenterology, Hassan II University Hospital, Faculty of Medicine and Pharmacy, Sidi Mohammed Ben Abdellah University of Fez, Fez, Morocco

Email: " charifiliass82@hotmail.com

Received 25 September 2013; revised 26 October 2013; accepted 14 November 2013

Copyright (C) 2013 Iliass Charif et al. This is an open access article distributed under the Creative Commons Attribution License, which permits unrestricted use, distribution, and reproduction in any medium, provided the original work is properly cited.

\begin{abstract}
The upper gastrointestinal bleeding from esophageal or gastric varices is the most dangerous complication of portal hypertension. The purpose of this study was to identify the predictors of early rebleeding and mortality after a bleeding episode. Patients and Methods: It was a retrospective study including 215 patients admitted in our department of hepatology and gastroenterology at the Hassan II University Hospital of Fez, from January 2001 to January 2010. Results: The mean age of our patients was 51 years. Thirty percent of patients had cirrhosis due to virus (B or C). The majority of patients $(79 \%)$ had only esophageal varices. Fifty patients (23\%) had a bleeding recurrence. Twenty-five patients $(11.5 \%)$ died during the first ten days, of which $\mathbf{5 2 \%}$ had presented rebleeding $(p=0.01)$. In $30 \%$ of cases, the rebleeding was secondary to a fall of pressure ulcers. Univariate analysis showed that early mortality of patients was significantly associated with advanced age $(p=0.018)$, low prothrombin time $(P T)(p=0.022)$, low serum sodium $(p=0.03)$, low platelet count $(p=0.05)$, and elevated transaminases $(p=0.02)$. Conclusion: The survival of cirrhotic patients after a bleeding episode was influenced by advanced age, a low rate of PT, of serum sodium, and of the platelet count, and elevated transaminases.
\end{abstract}

Keywords: Cirrhosis; Portal Hypertension; Gastrointestinal Bleeding; Esophageal Varices

\section{INTRODUCTION}

The upper gastrointestinal bleeding from esophageal var-

${ }^{*}$ Conflicts of interest: No conflicts of interest.

${ }^{\#}$ Corresponding author. ices is one of the most dangerous complications of portal hypertension, with a consistently high morbidity and mortality $[1,2]$. Despite advances in the management of variceal bleeding, mortality following a bleeding episode in cirrhotic patients has decreased by only $20 \%$ $[3,4]$. Several risk factors associated with mortality after a bleeding episode were identified. These factors are: active bleeding during the initial endoscopy, venous pressure gradient, portal vein thrombosis, alcoholic liver disease, bilirubin, albumin, hematocrit, transaminases, encephalopathy, hepatocellular carcinoma and Child Pugh score $[5,6]$. Many of these data were collected from retrospective studies where mortality after variceal bleeding was greater than $50 \%$. But these studies have included a relatively small number of patients, or groups with no standard treatment especially concerning the use of antibiotics [5,7,8]. Several prognostic scores have been developed in cirrhotic patients with variceal bleeding. Currently, the most used are the Child-Pugh score and MELD. Recent studies have demonstrated the ability of these scores to predict early mortality in these patients [9]. Given the significant changes in the natural history of cirrhosis from the broad and standardized use of antibiotic prophylaxis and endoscopic treatment, and given the etiological feature of cirrhosis in our population characterised by the high prevalence of viral cirrhosis, we have found that it is very interesting to investigate predictor factors of rebleeding and those involved in the short-term survival of cirrhotic patients with variceal bleeding.

\section{PATIENTS AND METHODS}

\subsection{Study Population}

We present a retrospective study of patients with cirrhosis and variceal bleeding, admitted in our department of hepatology and gastroenterology at the University Hos- 
pital of Fez, between January 2001 and January 2010. We have included only patients presenting a first bleeding episode. The diagnosis of cirrhosis was based on the combination of clinical, biological, endoscopic and ultrasonographic criteria. The diagnosis of variceal bleeding was confirmed by the presence of hematemesis and/or melena at admission of our patients, and the presence of varices at endoscopy with or without active bleeding and without any other causes of bleeding highlighted in the endoscopy. All patients were treated by esophageal varices ligature associated with an antibiotic prophylaxis based on cephalosporins, and transfusion if necessary. During the study period, no patients had received treatment with vasoactive drugs. We did not take into account the experience of the operator who performed the haemostatic action.

\subsection{Variables Studied}

All patients had received a biological assessment within 24 hours after the bleeding episode.

The variables studied were: age, sex, presence of ascites, encephalopathy, the presence of active bleeding, lesions found at endoscopy, the platelet count, transaminases, prothrombin, the etiology of cirrhosis and child.

Rebleeding was defined according to the criteria of Baveno V [10].

Early mortality was defined as death within 6 weeks after the bleeding episode.

\subsection{Statistical Methods}

We conducted a descriptive analysis of data using the Epi Info system and analytical one using the " $\mathrm{t}$ " Student test. We have considered $p<0.05$ as a significant value.

\section{RESULTS}

Between January 2001 and January 2010, 215 patients with cirrhosis were included. The clinical characteristics of patients are shown in Table 1. The average age was 51 years old, with an equal number of men and women. Forty-one percent of patients had viral cirrhosis B and $18 \%$ had viral cirrhosis C, $67 \%$ of patients had Child B and $22 \%$ had Child C. Forty-nine percent of patients had ascites. The majority of patients (82\%) had esophageal varices alone, and $18 \%$ had esophageal varices associated with gastric varices. Active bleeding at initial endoscopy was found in 66 patients $(30 \%)$. The mean hemoglobin level at admission was $8.7 \mathrm{~g} / \mathrm{dl}, 42 \%$ of patients had received a blood transfusion during the first 24 hours of hospitalization (Table 1).

Fifty patients (23\%) had rebleeding. Univariate analysis showed that rebleeding was significantly associated with the presence of a lowered prothrombin time $(\mathrm{p}=$ $0.05)$. Ascites was noted in $40 \%$ of patients with recur- rence of bleeding $(\mathrm{p}=0.1)$. The mean hemoglobin level was $8.7(p=0.2)$, with an average number of units transfused $2(p=0.1)$. The mean bilirubin was $16.85 \%(p$ $=0.41) .60 \%$ of patients with recurrence had a Child B (p $=0.2$ ). Active bleeding at initial endoscopy was noted in $34 \%$ of cases $(p=0.3)$ (Table 2$)$.

Twenty five $(11.5 \%)$ patients died during the first ten days, whose $52 \%$ had presented rebleeding $(\mathrm{p}=0.01)$; $30 \%$ were secondary to an ulcer fall $(\mathrm{p}=0.4)$. Univariate analysis showed also that early mortality of patients was significantly associated with advanced patients age $(\mathrm{p}=$ $0.018)$, low prothrombin time $(p=0.022)$, low serum sodium $(\mathrm{p}=0.03)$, low platelet count $(\mathrm{p}=0.05)$, and elevated transaminases $(p=0.02)$ (Table 3).

\section{DISCUSSION}

The rate of rebleeding in our study was $23 \%$, this rate is lower than that reported by Wang $\mathrm{M}$ et al. [11] in 2011 (35.8\%) and Ben-Ari Z et al. [12] in 1999 (44\%), but approximately equal to that reported in the study of Krig JE et al. [13] in 2009 (24\%). This difference could be due to a difference in treatment methods. Ben-Ari $Z$ and colleagues [12] treated their patients by blood transfu-

Table 1. Clinical and biological characteristics of the study population $(\mathrm{N}=215)$.

\begin{tabular}{|c|c|}
\hline Number of patients & 215 \\
\hline Male & $107(50 \%)$ \\
\hline Mean age & 51 ans \\
\hline \multicolumn{2}{|l|}{ Child } \\
\hline A & $24(11 \%)$ \\
\hline $\mathrm{B}$ & $145(67 \%)$ \\
\hline $\mathrm{C}$ & $48(22 \%)$ \\
\hline \multicolumn{2}{|l|}{ Cause of bleeding } \\
\hline Esophageal varices & $215(82 \%)$ \\
\hline Gastric varices + esophageal varices & $37(18 \%)$ \\
\hline \multicolumn{2}{|l|}{ Clinical caracteristics of bleeding } \\
\hline Melena & 13 \\
\hline Hematemesis & 75 \\
\hline Hématemesis + melena & 127 \\
\hline \multicolumn{2}{|l|}{ Etiology of cirrhosis } \\
\hline Virus B & $89(41 \%)$ \\
\hline Virus $\mathrm{C}$ & $38(18 \%)$ \\
\hline Others & $88(41 \%)$ \\
\hline Mean Hemoglobin (g/dl) & 8.7 \\
\hline Natremia (meq/l) & 135.7 \\
\hline Ascites & 105 \\
\hline Transfusion in the first 24 hours & $92(24 \%)$ \\
\hline Average number of units transfused & 1.17 \\
\hline Varices with red signs & 149 \\
\hline Varices with actif bleeding & $66(30 \%)$ \\
\hline
\end{tabular}


Table 2. Predictors of rebleeding: univariate analysis.

\begin{tabular}{|c|c|c|c|}
\hline & $\begin{array}{l}\text { No rebleeding: } \\
\qquad \mathrm{N}=165\end{array}$ & $\begin{array}{l}\text { Rebleeding: } \\
\quad \mathrm{N}=50\end{array}$ & $\mathrm{p}$ \\
\hline Mean age (an) & 51 ans & 50 ans & 0.7 \\
\hline Male $(\%)$ & $50 \%$ & $50 \%$ & 0.5 \\
\hline Ascites & $85(51 \%)$ & $20(40 \%)$ & 0.1 \\
\hline Hepatic encephalopathy & $11(6 \%)$ & $3(6 \%)$ & 0.5 \\
\hline Active bleeding & $49(29.7 \%)$ & $17(34 \%)$ & 0.6 \\
\hline $\begin{array}{c}\text { Esophageal varices } \\
\text { grade III }\end{array}$ & $68(41 \%)$ & $18(36 \%)$ & 0.5 \\
\hline Gastric varices & $27(16 \%)$ & $10(20 \%)$ & 0.5 \\
\hline Platelets & 107,805 & 109,608 & 0.8 \\
\hline $\begin{array}{l}\text { Glutamopyruvate } \\
\text { Transférase (GPT) }\end{array}$ & 48 & 68 & 0.2 \\
\hline Prothrombin time & $70 \%$ & $59 \%$ & 0.05 \\
\hline Child A & $17(10 \%)$ & $6(12 \%)$ & 0.6 \\
\hline Child B & $107(64 \%)$ & $34(68 \%)$ & 0.2 \\
\hline Child C & $43(26 \%)$ & $6(12 \%)$ & 0.03 \\
\hline
\end{tabular}

Table 3. Predictors of early mortality: univariate analysis.

\begin{tabular}{cccc}
\hline & $\begin{array}{c}\text { Patients survived } \\
\mathrm{N}=190\end{array}$ & $\begin{array}{c}\text { Patients died } \\
\mathrm{N}=25(11.6 \%)\end{array}$ & $\mathrm{p}$ \\
\hline Age (an) & 50.53 & 58.84 & 0.018 \\
Male (\%) & $51 \%$ & $40 \%$ & 0.3 \\
Ascites & $91(48 \%)$ & $14(56 \%)$ & 0.5 \\
Hepatic & $10(5.2 \%)$ & $4(16 \%)$ & - \\
encephalopathy & $37(19.5 \%)$ & $13(52 \%)$ & 0.01 \\
Rebleeding & 132,590 & 105,053 & 0.05 \\
Platelets & $69 \%$ & $57 \%$ & 0.02 \\
Prothrombin time & 44.6 & 114 & 0.02 \\
Glutamopyruvate & & 25 & 0.19 \\
Transférase (GPT) & 30 & 11.39 & 0.45 \\
Serum albumin & 9.68 & 132 & 0.03 \\
Serum creatinine & 136 & $2(14.2 \%)$ & 0.5 \\
Natremia & $6(42.8 \%)$ & \\
Child A & $245(13.2 \%)$ & $6(42.8 \%)$ & \\
Child B & $126(96.6 \%)$ & & \\
Child C & $31(17 \%)$ & & \\
\hline
\end{tabular}

sions and vasoactive drugs, and if failure, sclerosis of esophageal varices was performed. In the study of Wang $\mathrm{M}$ et al. [11], patients were also treated with blood transfusions, vaso active drugs and anti acids. However, Krige $\mathrm{JE}$ and colleagues [13] treated their patients by sclerosis of esophageal varices. In our study, all patients were treated by endoscopic band ligation. The comparison between these series allows us to conclude that endoscopic therapy may be effective in cirrhotic patients with bleeding esophageal varices, this should be confirmed by other studies. In the study by Wong et al. [11], univariate analysis revealed that a low albumin levels, high white blood cell count, score of Child B and C, the presence of ascites, and encephalopathy were predictors of rebleeding in cirrhotic patients, these results were similar to those found in several studies [14-18]. In our study, these factors were not significantly associated with rebleeding, and only a low rate of prothrombin was a predictor of recurrence. This result implies that the severity of coagulopathy may play a critical role in rebleeding. In the series of K Bambha et al. [19], the MELD score and the presence of platelet plug on varicose veins in the initial endoscopy were predictive of rebleeding. Stratification of patients according to the MELD score (MELD $\geq 18$ points, MELD $<18$ points) revealed a significant increase in the risk of rebleeding in patients with a MELD score $\geq 18$ points. Currently, there is no well-established model to accurately predict the survival of cirrhotic patients after an episode of gastrointestinal bleeding due to rupture of esophageal varices. One of the difficulties is that the prognosis for these patients is influenced not only by the severity of the bleeding episode itself, but also by the severity of the underlying liver disease. In our series, the advanced age of patients was predictive of mortality in the first six weeks after the bleeding episode, this was consistent with the series of Sempere L et al. [20] who found that age $\geq 65$ years was significantly associated with early mortality. This factor is probably related to some factors found in the elderly population, mainly the duration of progression of liver disease, and the greater difficulty of management of recurrent decompensation [21]. In this series, the presence of HCC, the incidence of infection during the bleeding episode, a Child score $\geq 10$ and MELD score $\geq 18$ were also associated with early mortality. Some authors suggest that the development of HCC may accelerate the course of liver disease [22]. These patients often have a portal vein thrombosis, rebleeding after endoscopic treatment and thus a higher risk of early mortality. This high mortality rate is probably secondary to the advanced state of the underlying cirrhosis and the difficulty of mastering portal hypertension resulting [23-25]. In the series of Bamba $\mathrm{K}$ et $a$, advanced Child score, MELD score $\geq 18$, the number of units transfused during the first 24 hours, the presence of ascites, an active bleeding at initial endoscopy, high transaminase levels and low serum sodium were predictive of early mortality. The last two parameters were also found in our study, which was consistent with other studies [26]. The occurrence of rebleeding during the first five days after the bleeding was significantly associated with early mortality in our series, a 
factor also reported in the series of Kamba et al. [19].

\section{CONCLUSION}

The degree of liver cell failure influenced the occurrence of rebleeding after an episode of variceal bleeding in cirrhotic patients. The advanced age of patients, low prothrombin time, low rates of serum sodium and of platelets count, and high transaminase rate were predictors of early mortality in these patients.

\section{REFERENCES}

[1] Graham, D.Y. and Smith, J.L. (1981) The course of patients after variceal hemorrhage. Gastroenterology, 80, 800-809.

[2] de Franchis, R. (2005) Evolving consensus in portal hypertension. Report of the Baveno IV consensus workshop on methodology of diagnosis and therapy in portal hypertension. Journal of Hepatology, 43, 167-176. http://dx.doi.org/10.1016/j.jhep.2005.05.009

[3] Chalasani, N., Kahi, C., Francois, F., et al. (2003) Improved patient survival after acute variceal bleeding: A multicenter, cohort study. American Journal of Gastroenterology, 98, 653-659. http://dx.doi.org/10.1111/j.1572-0241.2003.07294.x

[4] del Olmo, J.A., Pena, A., Serra, M.A., et al. (2000) Predictors of morbidity and mortality after the first episode of upper gastrointestinal bleeding in liver cirrhosis. Journal of Hepatology, 32, 19-24. http://dx.doi.org/10.1016/S0168-8278(01)68827-5

[5] D'Amico, G. and De Franchis, R. (2003) Upper digestive bleeding in cirrhosis. Post-therapeutic outcome and prognostic indicators. Hepatology, 38, 599-612. http://dx.doi.org/10.1053/jhep.2003.50385

[6] Moitinho, E., Escorsell, A., Bandi, J.C., et al. (1999) Prognostic value of early measurements of portal pressure in acute variceal bleeding. Gastroenterology, 117, 626631. http://dx.doi.org/10.1016/S0016-5085(99)70455-5

[7] Le Moine, O., Adler, M., Bourgeois, N., et al. (1992) Factors related to early mortality in cirrhotic patients bleeding from varices and treated by urgent sclerotherapy. Gut, 33, 1381-1385. http://dx.doi.org/10.1136/gut.33.10.1381

[8] Siringo, S., McCormick, P.A., Mistry, P., et al. (1991) Prognostic significance of the white nipple sign in variceal bleeding. Gastrointestinal Endoscopy, 37, 51-55. http://dx.doi.org/10.1016/S0016-5107(91)70621-4

[9] Wiesner, R., Edwards, E., Freeman, R., Harper, A., Kim, R., Kamath, P., et al. (2003) Model for end-stage liver disease (MELD) and allocation of donor livers. Gastroenterology, 124, 91-96. http://dx.doi.org/10.1053/gast.2003.50016

[10] de Franchis, R. (2010) Revising consensus in portal hypertension: Report of the Baveno $\mathrm{V}$ consensus workshop on methodology of diagnosis and therapy in portal hypertension. Journal of Hepatology, 53, 762-768. http://dx.doi.org/10.1016/j.jhep.2010.06.004
[11] Wang, M.-T., Liu, T., Ma, X.-Q. and He, J. (2011) Prognostic factors associated with rebleeding in cirrhotic inpatients complicated with esophageal variceal bleeding. Chinese Medical Journal, 124, 1493-1497.

[12] Ben-Ari, Z., Cardin, F., McCormick, A.P., Wannamethee, G. and Burroughs, A.K. (1999) A predictive model for failure to control bleeding during acute variceal haemorrhage. Journal of Hepatology, 31, 443-450. http://dx.doi.org/10.1016/S0168-8278(99)80035-X

[13] Krige, J.E., Kotze, U.K., Distiller, G., Shaw, J.M. and Bornman, P.C. (2009) Predictive factors for rebleeding and death in alcoholic cirrhotic patients with acute variceal bleeding: A multivariate analysis. World Journal of Surgery, 33, 2127-2135. http://dx.doi.org/10.1007/s00268-009-0172-6

[14] Liu, J.S. and Liu, J. (2009) Comparison of emergency endoscopic variceal ligation plus octride or octride alone for acute esophageal variceal bleeding. Chinese Medical Journal, 122, 3003-3006.

[15] Huang, L.Y., Cui, J., Wu, C.R. and Liu, Y.X. (2007) Embolization combined with endoscopic variceal ligation for the treatment of esophagogastric variceal bleeding in patients with cirrhosis. Chinese Medical Journal, 120, 36-40.

[16] Heresbach, D., Bretagne, J.F., Raoul, J.L., Chaperon, J., Piette, C., Siproudhis, L., et al. (1991) Prognosis and prognostic factors of hemorrhage by rupture of varices in cirrhotic patients in the era of endoscopic sclerotherapy. Gastroentérologie Clinique et Biologique, 15, 838-844.

[17] Bosch, J., Berzigotti, A., Garcia-Pagan, J.C. and Abraldes, J.G. (2008) The management of portal hypertension: Rational basis, available treatments and future options. Journal of Hepatology, 48, s68-s92.

http://dx.doi.org/10.1016/j.jhep.2008.01.021

[18] Thomopoulos, K., Theocharis, G., Mimidis, K., Lampropoulou-Karatza, Ch., Alexandridis, E. and Nikolopoulou, V. (2006) Improved survival of patients presenting with acute variceal bleeding. Prognostic indicators of short- and long-term mortality. Digestive and Liver Disease, 38, 899-904.

http://dx.doi.org/10.1016/j.dld.2006.08.002

[19] Bambha, K., Kim, W.R., Pedersen, R., et al. (2008) Predictors of early rebleeding and mortality after acute variceal haemorrhage in patients with cirrhosis. Gut, 57, 814820. http://dx.doi.org/10.1136/gut.2007.137489

[20] Sempere, L., Palazón, J.M. and Sánchez-Payá, J. (2009) Assessing the short- and long-term prognosis of patients with cirrhosis and acute variceal bleeding. Revista Española de Enfermedades Digestivas, 101, 236-248.

[21] Prieto, M., Clemente, G., Casafont, F., Cuende, N., Cuervas-Mons, V., Figueras, J., et al. (2003) Consensus document on indications for liver transplantation. 2002. Gastroenterol Hepatol, 26, 355-375. http://dx.doi.org/10.1157/13048890

[22] D'Amico, G., Garcia-Tsao, G. and Pagliaro, L. (2006) Natural history and prognostic indicators of survival in cirrhosis: A systematic review of 118 studies. Journal of Hepatology, 44, 217-231. http://dx.doi.org/10.1016/j.jhep.2005.10.013 
[23] D'Amico, G., De Franchis, R. and Cooperative Study Group (2003) Upper digestive bleeding in cirrhosis. Posttherapeutic outcome and prognostic indicators. Hepatology, 38, 599-612.

http://dx.doi.org/10.1053/jhep.2003.50385

[24] Yeo, W., Sung, J.Y., Ward, S.C., Chung, S.C., Lee, W.Y., Li, A.K., et al. (1995) A prospective study of upper gastrointestinal hemorrhage in patients with hepatocellular carcinoma. Digestive Diseases and Sciences, 40, 25162521. http://dx.doi.org/10.1007/BF02220435

[25] Sung, J.J., Yeo, W., Suen, R., Lee, Y.T., Chung, S.C.,
Chan, F.K., et al. (1998) Injection sclerotherapy for variceal bleeding in patients with hepatocellular carcinoma: Cyanoacrylate versus sodium tetradecyl sulphate. Gastrointestinal Endoscopy, 47, 235-239. http://dx.doi.org/10.1016/S0016-5107(98)70319-0

[26] D’Amico, G., Garcia-Tsao, G. and Pagliaro, L. (2006) Natural history and prognostic indicators of survival in cirrhosis: A systematic review of 118 studies. Journal of Hepatology, 44, 217-231.

http://dx.doi.org/10.1016/j.jhep.2005.10.013 